\title{
Contemporaneidade de PaUlo Freire na educaÇão de JoVens e ADULTOS NO BRASIL: UM ESTUDO BIBLIOGRÁFICO
}

\author{
PAULO FREIRE'S CONTEMPORANEITY IN YOUTH AND ADULT'S EDUCATION IN BRAZIL: A \\ BIBLIOGRAPHIC RESEARCH
}

LA CONTEMPORANEIDAD DE PAULO EN LA EDUCACIÓN DE JÓVENES Y ADULTOS EN BRASIL: UNA INVESTIGACIÓN BIBLIOGRÁFICA

\author{
Adenilda Rodrigues da \\ Silva Junqueira

\section{iD 9} \\ Mestranda em educação \\ Profissional e Tecnológica- \\ ProfEPT \\ Pedagoga do Instituto Federal de \\ Educação, Ciência e Tecnologia \\ Goiano (IF Goiano) - Campus \\ Iporá \\ adenilda.junqueira@ifgoiano.edu.b \\ $\underline{\mathrm{r}}$
}

\section{José Carlos Moreira de Souza \\ (iD) 9}

Doutor em Educação

Docente do Instituto Federal de

Educação, Ciência e Tecnologia

Goiano (IF Goiano) - Campus

Ceres

Docente do Programa de Pós-

Graduação em Educação

Profissional e Tecnológica -

ProfEPT

jose.moreira@ifgoiano.edu.br

\begin{abstract}
Resumo
O objetivo deste artigo é discutir as contribuições teóricometodológicas formuladas pelo intelectual e educador brasileiro Paulo Freire (1921-1997) acerca da modalidade Educação de Jovens e Adultos. A discussão é amparada em estudo bibliográfico relacionado às teorias elaboradas por Paulo Freire. Inicialmente, foram elencados marcos teóricos desta modalidade, relacionando-a ao contexto histórico, para apreender a sua importância político-econômica na sociedade atual. Embora o método originalmente desenvolvido e aplicado por Paulo Freire não seja predominante nas práticas pedagógicas na EJA, sua influência teórico-conceitual ainda é predominante em diferentes pesquisas do campo educacional brasileiro e também mundo afora. O presente texto faz um recorte da referida teoria educacional, as contribuições, sua aplicação no processo de ensino-aprendizagem da EJA, trazendo uma reflexão no papel social da escola, sobretudo no tempo contemporâneo, evidenciando a possibilidade da inclusão dos sujeitos da EJA a partir da apropriação dos conhecimentos em decorrência da educação.
\end{abstract}

Palavras-chave: Paulo Freire. Educação de Jovens e Adultos. Marcos Teóricos. Contemporâneo.

Recebido em: 9 de abril de 2021.

Aprovado em: 3 de junho de 2021.

Como citar esse artigo (ABNT):

JUNQUEIRA, Adenilda Rodrigues da Silva; SOUZA, José Carlos Moreira de. Contemporaneidade de Paulo Freire na educação de jovens e adultos no Brasil: um estudo

bibliográfico. Revista Prática Docente, v. 6, n. 2, e038, 2021. http://doi.org/10.23926/RPD.2021.v6.n2.e038.id1088 


\begin{abstract}
The aim of this article is to discuss the theoretical and methodological contributions made by the Brazilian intellectual and educator Paulo Freire (1921-1997) about the Youth and Adult Education modality. The discussion is supported by a bibliographic study related to the theories elaborated by Paulo Freire. Initially, theoretical frameworks of this modality were listed, relating it to the historical context, in order to apprehend its political-economic importance in today's society. Although the method originally developed and applied by Paulo Freire is not predominant in pedagogical practices in EJA, its theoretical and conceptual influence is still prevalent in different researches in the Brazilian educational field and also around the world. This text makes a cut of the aforementioned educational theory, the contributions, its application in the teaching-learning process of EJA, bringing a reflection on the social role of the school, especially in contemporary time, showing the possibility of including the subjects of EJA from the appropriation of knowledge as a result of education.
\end{abstract}

Keywords: Paulo Freire. Youth and Adults Educational. Theoretical Marks. Contemporary.

\title{
Resumen
}

El objetivo de este artículo es discutir los aportes teóricos y metodológicos del intelectual y educador brasileño Paulo Freire (1921-1997) sobre la modalidad de Educación de Jóvenes y Adultos. La discusión se sustenta en un estudio bibliográfico relacionado con las teorías elaboradas por Paulo Freire. Inicialmente, se enumeraron los marcos teóricos de esta modalidad, relacionándola con el contexto histórico, para aprehender su importancia político-económica en la sociedad actual. Si bien el método originalmente desarrollado y aplicado por Paulo Freire no es predominante en las prácticas pedagógicas en EJA, su influencia teórica y conceptual aún prevalece en diferentes investigaciones en el campo educativo brasileño y también en todo el mundo. Este texto hace un corte de la mencionada teoría educativa, los aportes, su aplicación en el proceso de enseñanza-aprendizaje de EJA, trayendo una reflexión sobre el rol social de la escuela, especialmente en la época contemporánea, mostrando la posibilidad de incluir las asignaturas de EJA a partir de la apropiación de conocimientos como resultado de la educación.

Palabras Clave: Paulo Freire. Educación de Jóvenes y Adultos. Hitos teóricos. Contemporáneo. 


\section{INTRODUÇÃO}

Este artigo resultante de estudo bibliográfico é parte da pesquisa de mestrado intitulada: "Memórias e narrativas de egressos/as do PROEJA, no Instituto Federal Goiano - Campus Iporá”. A pesquisa tem como objetivo avaliar como a universalização da educação básica tem sido pauta dos compromissos assumidos pelo Estado brasileiro, especialmente nas últimas décadas do século XX e nesse início de século XXI, notadamente frente aos organismos internacionais, a partir da avaliação da implementação da modalidade numa instituição de educação básica, técnica e tecnológica, como apontado por Gadotti (2008).

O contexto histórico em que está inserido a educação de jovens e adultos, conforme avaliação de Ramos (2014), é marcado por políticas públicas descontinuadas e rupturas de programas, que operam de acordo com as mudanças nos cenários políticos. Segundo dados do Instituto Brasileiro de Geografia e Estatística (IBGE, 2019), ainda hoje, o Brasil não conseguiu garantir o direito constitucional à educação básica a todas as pessoas.

Conforme dados do IBGE (2020), a Pesquisa Nacional por Amostra de Domicílios Contínua (PNAD Contínua), em 2019, demostrou que aproximadamente 6,6\% dos brasileiros, com idade de 15 anos ou mais, ainda estão na condição de não escolarizados: isto representa 11 milhões de pessoas vivendo à margem da sociedade letrada. Houve uma redução de $0,2 \%$ se compararmos com os dados de 2018. Esta questão se agrava ao analisar regionalidades diferentes, sendo os índices mais expressivos na região Nordeste, que alcança 13,9\% da população com idade de 15 anos ou mais, um percentual maior que aqueles verificado nas regiões como Sul e Sudeste, que apresentam índices de 3,3\% da população sem nenhuma instrução.

Neste sentido, outro recorte importante da Pesquisa Nacional por Amostra de Domicílios tem relação ao local de domicílio, pois, a população rural concentra a maior parte dos não escolarizados, com índice até três vezes superior ao verificado na população urbana. Além das desigualdades entre as regiões do país, outros indicadores devem ser considerados, como o fator cor ou raça, onde se observa que $8,9 \%$ são declarados negros e pardos, que chega a ser um índice quase três vezes maior do que o dos declarados brancos, de 3,6\%.

Em 2019, os dados do IBGE apontaram que quase 75\% dos jovens entre 18 a 24 anos estão atrasados no que toca à relação idade-série ou abandonaram a escola. Outro recorte preocupante remonta à desigualdade de acesso e permanência entre a população declarada branca e preta/parda continua muito elevada, sendo um dos fatores apontados para o abandono 
dos estudos a necessidade que estes jovens têm de trabalhar para contribuir com o sustento da família. No entanto, quanto à evasão escolar dos sujeitos declarados pretos/pardos, há outros fatores que podem contribuir para a evasão. Munanga (2005) sustenta que o despreparo de todo o sistema educacional, inclusive do professor, tende a promover esta evasão.

[...] o preconceito incutido na cabeça do professor e sua incapacidade em lidar profissionalmente com a diversidade, somando-se ao conteúdo preconceituoso dos livros e materiais didáticos e às relações preconceituosas entre alunos de diferentes ascendências étnico-raciais, sociais e outras, desestimulam o aluno negro e prejudicam seu aprendizado. O que explica o coeficiente de repetência e evasão escolar altamente elevado do alunado negro, comparativamente ao do alunado branco (MUNANGA, 2005, p.16).

Em relação ao recorte de gênero, é possível perceber que, em todos os indicadores listados a seguir, as mulheres têm alcançado índices melhores, o que permite concluir que mesmo com as dificuldades apontadas anteriormente, como gravidez e predominância na execução dos afazeres domésticos, elas estão se qualificando e elevando os níveis de escolaridade, apresentando indicadores superiores àqueles verificados na população masculina, como observado na Tabela 1.

Tabela 1 - Taxa de analfabetismo e defasagem escolar

\begin{tabular}{cccccc}
\hline & Brasil & Brancos & $\begin{array}{c}\text { Pretos/ } \\
\text { pardos }\end{array}$ & Homens & Mulheres \\
\hline Taxa de analfabetismo & $6,6 \%$ & $3,6 \%$ & $8,9 \%$ & $6,9 \%$ & $6,3 \%$ \\
\hline $\begin{array}{c}\text { Frequência escolar } \\
\text { adequada }\end{array}$ & $21,4 \%$ & $29,7 \%$ & $16,1 \%$ & $18,4 \%$ & $24,5 \%$ \\
\hline $\begin{array}{c}\text { Atraso escolar dos } \\
\text { estudantes }\end{array}$ & $11 \%$ & $8,2 \%$ & $12,7 \%$ & $12,3 \%$ & $9,7 \%$ \\
\hline $\begin{array}{c}\text { Concluiu a educação } \\
\text { básica }\end{array}$ & $4,1 \%$ & $6,0 \%$ & $2,8 \%$ & $3,1 \%$ & $5,1 \%$ \\
\hline $\begin{array}{c}\text { Não frequenta escola e não } \\
\text { concluiu a educação básica }\end{array}$ & $63,5 \%$ & $56,1 \%$ & $68,3 \%$ & $66,3 \%$ & $60,7 \%$ \\
\hline
\end{tabular}

Fonte: IBGE, 2020.

A formação integral no percurso do Programa Nacional de Integração da Educação Profissional com a Educação Básica, na Modalidade de Jovens e Adultos (Proeja), aproximase da educação humanista e libertadora que objetivava Paulo Freire, na prática de ensino e alfabetização de jovens e adultos, e como isso tem influenciado na vida do professor e do estudante envolvidos nesta modalidade.

Deste modo, inicialmente buscou-se elencar alguns marcos teóricos da EJA no Brasil; em seguida, posteriormente evidenciar as contribuições do educador Paulo Freire para a modalidade EJA, entendendo a educação como ato político e, por sua natureza, estar em 
constante disputa ideológica de acordo com o projeto societário em vigor; são discutidas as concepções de educação, ensino e aprendizagem em disputa no campo da EJA, como terceiro momento; e, enfim, contemplar o objetivo deste artigo através do conteúdo, da discussão e das análises a partir de pesquisa bibliográfica.

A EJA é uma modalidade de ensino ofertada para aqueles que, em algum momento, foram excluídos do processo educacional, seja por motivos sociais, políticos ou culturais. Assim, pode-se dizer que a instituição escola fracassa com esse público que é, geralmente, oriundo de classes abandonadas pelo Estado, cresce com condições precárias, diferente da elite, que tem em casa o suporte para complementação de suas horas de estudo. Para Paiva, Machado e Ireland (2006), há uma diversidade expressiva no público da EJA, que está em um processo de transformação do perfil por faixa etária, expectativa e comportamento.

Trata-se de um jovem ou adulto que historicamente vem sendo excluído, quer pela impossibilidade de acesso à escolarização, quer pela sua expulsão da educação regular ou mesmo da supletiva pela necessidade de retornar aos estudos. Não é só o aluno adulto, mas também o adolescente; não apenas aquele já inserido no mercado de trabalho, mas o que ainda espera nele ingressar; não mais o que vê a necessidade de um diploma para manter sua situação profissional, mas o que espera chegar ao ensino médio ou à universidade para ascender social e profissionalmente (PAIVA; MACHADO; IRELAND, 2006, p. 19).

Uma observação importante é a de que "todos vão à escola e ali competem; mas o menino rico, não tem jamais que lutar pelo sustento, nem de cuidar dos irmãos" (RIBEIRO, 2018, p. 22); assim, as adversidades da escola considerada elitista eliminam ou menosprezam as perspectivas educacionais das classes sociais consideradas populares.

Institucionalmente, a EJA, modalidade de educação que pode ser considerada reparadora uma vez que, conforme indica Oliveira (1999), está voltada para os que se encontram na condição de exclusão social, econômica, educacional e cultural. Assim, a EJA busca suprir as necessidades educacionais oferecendo o Ensino Fundamental para aqueles que têm idade mínima de 15 anos completos, e também o Ensino Médio para aqueles que já completaram os 18 anos de idade. Os objetivos da EJA perpassam por atender demandas do mercado e também ao ideário legitimador do projeto em sociedade em vigor, como afirmado por Fávero (2011):

[...] a educação, especialmente nos últimos 150 anos, serviu - no seu todo - ao propósito de não só fornecer os conhecimentos e o pessoal necessário à máquina produtiva em expansão do sistema do capital, como também gerar e transmitir um quadro de valores que legitima os interesses dominantes, como se não pudesse haver nenhuma alternativa à gestão da sociedade, seja na forma internalizada, pelos indivíduos devidamente educados e aceitos, seja por meio de uma dominação estrutural e uma subordinação hierárquica implacavelmente imposta (FÁVERO, 2011, p. 369). 
Além disso, as dificuldades de aprendizagem, as condições sociais, a necessidade de trabalhar e outros fatores fazem milhares de jovens abandonarem a escola ainda no Ensino Fundamental, não concluindo nem a Educação Básica. De acordo com dados do IBGE (2020), mais de 3,2 milhões de jovens de 19 anos, apenas 63,5\% concluíram o Ensino Médio, cerca de quase 1,2 milhões ainda não concluíram e, se formos referenciar a idade regular para conclusão do Ensino Médio, a situação é ainda mais preocupante: desses jovens que não terminaram o Ensino Médio, 62\% nem frequentam mais a escola e quase a metade destes parou os estudos ainda no Ensino Fundamental.

O contexto histórico da educação no Brasil perpassou por diversos estágios, avanços, retrocessos, além de ações arbitrárias nos diferentes governos desde o império, governos militares e a retomada da redemocratização. Para Germano (1993), os primeiros anos do governo militar, na fase de 1964 à 1974, foram caracterizados pela ascensão e consolidação do regime militar; e nas políticas educacionais são acentuadas ações autoritárias e burocráticas, provocando uma ruptura no que se vinha debatendo em termos de educação popular no Brasil com educadores como Paulo Freire.

As reformas na política educacional verificadas no contexto dos anos de 1964 a 1985, foi condição necessária para a manutenção do governo militar, pois

[...] o estado militar necessita de bases de legitimação, da adesão de uma parte dos
intelectuais, das camadas médias e das massas populares. Daí os apelos constantes à
democracia e à liberdade, quando estas eram duramente golpeadas por ele; daí a
proclamação em favor da erradicação da miséria social quando, na prática, as suas
políticas concorriam para manter ou mesmo aumentar, de forma dramática, os índices
de pobreza relativa - mesmo num contexto de crescimento econômico - mediante a
intensificação da exploração da força de trabalho, da concentração desmedida da
renda e da manutenção de um numeroso exército industrial de reserva (GERMANO,
1990, p. 139 - 140).

Neste sentido, a pedagogia de viés tecnicista foi a que mais atendeu durante o período desenvolvimentista, pois a política nacional almejava o aprimoramento de habilidades e competências para o desenvolvimento do país:

\footnotetext{
No pressuposto da neutralidade científica e inspirada nos princípios de racionalidade, eficiência e produtividade, a pedagogia tecnicista advoga a reordenação do processo educativo de maneira que o torne objetivo e operacional. De modo semelhante ao que ocorreu no trabalho fabril, pretende-se a objetivação do trabalho pedagógico (SAVIANI, 2007, p. 379).
}

A apropriação de propostas para o campo educacional, de natureza populista, mesmo que somente no discurso, agrega no sentido da legitimação do governo militar. Propostas de expansão e popularização da educação com ênfase na erradicação do analfabetismo foram 
fortemente divulgadas, mesmo que, na prática, o segmento da educação sofria fortes represálias políticas e escassez de verbas.

[...] em decorrência, o regime político excludente define um dos seus projetos de equalização social, produz discurso de valorização da educação e transforma a política educacional numa estratégia de hegemonia, num veículo para a obtenção de consenso (GERMANO, 1990, p. 142).

A área da educação de adultos teve influência de Paulo Freire, para quem rendeu além do exílio e a perseguição "valeu também compreensão e apoio de estudantes, de intelectuais, de homens simples do povo, engajados todos eles no esforço de humanização e libertação do homem e da sociedade brasileira" (FREIRE, 1992, p. 37). Educação como maneira de conhecer a própria realidade, como prática de liberdade, e, a partir de então, poder intervir com a finalidade de mudar essa realidade. Paulo Freire, naquela época, foi o "educador que, naqueles anos, melhor sintetizou e sistematizou o essencial das propostas educativas de então, no primeiro momento, como um sistema de educação de adultos, experimentado na sua primeira fase de alfabetização" (FÁVERO, 2007, p. 40). Paulo Freire, por causa de sua ideia de educação e suas práticas de cunho político e social, confrontava os ideais autoritários do governo militar.

A coragem de pôr em prática um autêntico trabalho de educação, que identifica a
alfabetização como um processo de conscientização, capacitando o oprimido tanto
para a aquisição dos instrumentos de leitura e escrita quanto para a sua libertação, fez
dele um dos primeiros brasileiros a serem exilados. A metodologia por ele
desenvolvida foi muito utilizada no Brasil em campanhas de alfabetização e, por isso,
ele foi acusado de subverter a ordem instituída, sendo preso após o Golpe Militar de
1964 (GADOTTI; ABRÂO, 2012, p.10).

Anos depois, ao retornar ao Brasil, Paulo Freire seguiu a carreira pedagógica ${ }^{1}$, influenciou diversas práticas de ensino, favorecendo assim a inclusão dos indivíduos na sociedade letrada. Atualmente, conforme exposto pelo Ministério da Educação e do Desporto (2001), a EJA é uma modalidade amparada por lei, sendo uma prática de caráter político, devido a seu objetivo de solucionar situações de exclusão social.

O ser humano é um ser social, que está sempre apto a aprender, inovar, criar, e, por meio da educação, é possível agregar conhecimento e definir sua identidade. Logo, a educação é instrumento de socialização. Nesse sentido, para Paulo Freire, o professor é um profissional que trabalha com a pedagogia da esperança, e isso acontece porque o aluno é parte fundamental de

\footnotetext{
1 Paulo Freire retorna ao Brasil em julho de 1980, aos 57 anos, e fixou residência em São Paulo. Aceitou o convite para lecionar na Faculdade de Educação da Unicamp, em Campinas, e logo depois ingressou no Programa de Estudos Pós-Graduados em Educação (supervisão e currículo) da PUC-SP. Paulo Freire participa da fundação do Vereda - Centro de Estudos em Educação, também em São Paulo, cujo objetivo era desenvolver pesquisas, prestar assessoria e atuar na formação de professores dedicados à prática da educação popular. (PROJETO MEMÓRIA, [s. d.])
} 
todo o trabalho. Ele indaga sobre a necessidade de os educadores impulsionarem a busca pelos sonhos, na razão de ter esperança de mudança a partir da percepção e do pensamento crítico. Assim, "sonhar não é apenas um ato político necessário, mas também uma conotação da forma histórico-social de estar sendo de mulheres e homens. Faz parte da natureza humana que, dentro da história, se acha em permanente processo de tornar-se" (FREIRE, 1992, p. 47).

Assim, a partir do contexto do estudante trabalhador, ensinando conceitos e palavras que fazem sentido para o estudante, para uma educação com intencionalidade política que enquanto alfabetiza também conscientiza o aluno de quem ele é, da sua situação de oprimido, e provoca o desenvolvimento de sua criticidade, para Freire o caminho da pedagogia humanista e libertadora perpassa por dois momentos distintos sendo:

o primeiro, em que os oprimidos vão desvelando o mundo da opressão e vão comprometendo-se na práxis, com a sua transformação; o segundo, em que, transformada a realidade opressora, esta pedagogia deixa de ser do oprimido e passa a ser a pedagogia dos homens em processo de permanente libertação (FREIRE, 1987, p. 27)

Para Paulo Freire, a relação entre professor e aluno tem que ser uma relação dialógica, para contribuir com a desconstrução de concepções opressoras fundadas em preconceitos e no conformismo. Ele defende também o direito de todos à alfabetização e educação, que, antes da leitura da palavra, é preciso fazer uma leitura crítica da própria realidade, sendo preciso fazer um esforço mútuo para essa compreensão, uma autoconsciência, ou seja, uma percepção do mundo e de si mesmo; isso porque a educação vai além dos objetivos de ensino, podendo levar o aluno à socialização, à emancipação e ao questionamento sobre sua condição de marginalização.

\footnotetext{
A leitura do mundo precede a leitura da palavra, daí que a posterior leitura desta não possa prescindir da continuidade da leitura daquele. Linguagem e realidade se prendem dinamicamente. A compreensão do texto a ser alcançada por sua leitura crítica implica a percepção das relações entre o texto e o contexto (FREIRE, 1989, p. 9).
}

Para Paulo Freire, a educação de adultos vai se aproximando da educação popular, o que a torna mais abrangente, e a realidade começa a fazer algumas exigências à sensibilidade e à competência científica dos educadores. A educação popular contribui para que a compreensão do homem como ser social seja mais diversificada e aberta à discussão democrática de pressuposições básicas da existência. Essa preocupação de Paulo Freire era para contribuir com "uma prática educativa e uma reflexão pedagógica que tornasse o mundo menos malvado" (FREIRE, 2001, p. 16-17). 
Freire defendeu a cultura, a educação e a expressão, trabalhou com temas geradores que, a partir do diálogo com os alunos, pode levantar temas do contexto dos estudantes que tornam o ensino significativo para os estudantes e, a partir de então, eles sejam capazes de lutar pela mudança no seu contexto social. Essa questão da busca de uma formação que vai além da capacidade de decifrar símbolos e juntar letras se aproxima da formação integral almejada pelos cursos que agregam formação profissional e formação básica, buscando ressignificar os sentidos do trabalho.

\section{Marcos Teóricos da EduCAÇÃo de JovenS E AdUltos No BraSIL}

A EJA é uma modalidade de Ensino Fundamental e Médio destinada a jovens e adultos que não tiveram acesso ao ensino na idade regular, ou, quando acessavam, esse processo se efetivava em moldes acelerados e precários: a sala de aula em condições precárias, com professores sem qualificação específica para o ensino da educação de jovens e adultos, sem garantir a esses sujeitos o direito de iniciar ou dar continuidade a sua formação acadêmica, que proporcionaria a eles novas oportunidades. Os fatores que levam esses sujeitos de volta ao contexto escolar são vários, e, dentre eles, é possível destacar a vontade de melhorar as suas condições de vida e de trabalho.

Desde o período colonial, a escola era prerrogativa das camadas sociais economicamente privilegiadas. Logo, as classes de baixo poder aquisitivo não tinham acesso à educação. Para Strelhow (2010), neste período, a educação de jovens e adultos era tida como um ato de caridade das pessoas letradas para as outras tidas como "perigosas e degeneradas"; assim, a educação de jovens e adultos passa a ser um ato de bondade e não mais um direito.

Conforme a análise de Scortegagna e Oliveira (2006), quando aconteceu a transição político-administrativa, do Império para o estado republicano, mais uma vez a educação foi motivo de debate, desta vez considerada algo importante para o desenvolvimento dos brasileiros, pois

\footnotetext{
A educação ganha novos impulsos sob a crença de que seria necessário educar o povo para que o país se desenvolvesse, assim como para participar politicamente através do voto, que se daria por meio da incorporação da enorme massa de analfabetos (SCORTEGAGNA; OLIVEIRA, 2006, p. 4).
}

A constituição de 1824, sendo influenciada pela Europa e ideias iluministas, tinha, em seu texto, a garantia de uma "instrução primária e gratuita para todos os cidadãos" (BRASIL, 1824; HADDAD; DI PIERRO, 2000), o que incluía os adultos. No entanto, não houve efetividade nas ações de alfabetização de jovens e adultos nesse período. Muito se debateu em 
uma forma de levar a instrução básica ao público marginalizado, sendo que faziam parte deste público homens e mulheres pobres, negros escravos e libertos e índios.

Neste sentido, somente em 1879, durante o Brasil Império, ocorrem as primeiras reformas educacionais, e, nelas, há menção a políticas educacionais voltadas para adultos analfabetos. Por meio do Decreto $\mathrm{n}^{\circ} 7.247$ de 1879, Leôncio de Carvalho estabeleceu "[...] o oferecimento de cursos para adultos analfabetos [...]” (MELO; MACHADO, 2009, p. 297).

Em 1934, em um ato de descentralização em relação à educação, os estudos primários e secundários são deixados a cargo das províncias, o que reforçou a questão da dualidade na educação. Essas províncias, por sua vez, não tinham recursos para investir na educação da maioria da população, e a União reservou o ensino secundário e superior às elites.

Strelhow (2010) observa que, no início do século XX, os analfabetos representavam grande parte da população e as políticas e ações para mitigar essa situação, no início da nova República, não tiveram grandes resultados, pois as políticas não vinham com subsídios financeiros para efetivar as ações na democratização do ensino. O censo de 1920 aponta para o alarmante dado sobre o analfabetismo no Brasil. Esse analfabetismo era muito superior em relação aos de países da América Latina e de outros países desenvolvidos. A população analfabeta acima de cinco anos estava em torno de $72 \%$. Fazia-se necessário alfabetizar a pessoa analfabeta, capaz de contribuir com o desenvolvimento do país, tornando-se um ser produtivo.

Fávero (2011) observa que o primeiro trabalho de educação de jovens e adultos no Brasil copiou modelos internacionais de países como Inglaterra, França e Estados Unidos, época em que foram implantadas redes de ensino não sistematizadas chamadas extraescolares. O objetivo principal era reduzir o analfabetismo, em que se ofertava cursos noturnos aligeirados, que dispunham de parcos recursos financeiros para sua manutenção, algo que se assemelha com as políticas públicas, ou ausência delas, para o público de jovens e adultos vigentes na organização da política educacional atualmente vigente.

Já na Era Vargas (1930-1954), “com a consolidação do capitalismo no país, devido ao avanço do setor industrial e o consequente deslocamento populacional para os centros urbanos, mudou o perfil da sociedade brasileira" (CAIRES; OLIVEIRA, 2016, p. 595), tornando fundamental a instauração de políticas educacionais que atendessem ao novo modelo de organização social vigente. com um crescente processo de industrialização no Brasil, há uma demanda por mão de obra qualificada para operar as novas máquinas nas fábricas e uma das 
formas de tentar responder a demanda desse novo regime foi a instituição da dualidade no ensino, sendo instituído o ensino técnico comercial.

A tentativa de responder a "necessidade" de formação técnico-profissional precoce, sem comprometer a qualidade e a função educativa do ensino secundário, parece não ter deixado outra opção senão a oficialização da dualidade dentro do próprio sistema público de ensino, configurando o ensino técnico comercial como um ramo do ensino médio, sem qualquer articulação com o ramo secundário e o ensino superior (XAVIER, 1990, p. 91).

Em 1938, cria-se o Instituto Nacional de Estudos Pedagógicos (INEP), que trouxe contribuições, a partir de suas pesquisas, para a consolidação de um Fundo Nacional do Ensino Primário, o qual objetivava a realização de programas de ensino para incluir o Ensino Supletivo para adolescentes e adultos. Como anota Lourenço Filho (1945, apud FÁVERO, 2011), as décadas de 1940 e 1950, a educação de jovens e adultos se destacou na ordem de prioridades dos governos do período. Merecem destaque a função supletiva, de combate ao analfabetismo, a função profissional, aperfeiçoando a cultura e os meios de produção, e a função cívico-social integrando os migrantes do país e imigrantes estrangeiros.

Com a promulgação da primeira Lei de Diretrizes e Bases da Educação Nacional, a Lei $\mathrm{n}^{\circ}$ 4024, de 20 dezembro de 1961, e a aprovação do Plano Nacional de Educação, criaram-se condições para novos debates e experiências na educação de jovens e adultos no Brasil, até então voltadas para os processos de leitura, escrita e aprendizagens matemáticas, conforme previu a legislação daquela ocasião:

Art. 20. Na organização do ensino primário e médio, a lei federal ou estadual atenderá:

a) à variedade de métodos de ensino e formas de atividade escolar, tendo-se em vista as peculiaridades da região e de grupos sociais

b) ao estímulo de experiências pedagógicas com o fim de aperfeiçoar os processos educativos.

Art. 25. O ensino primário tem por fim o desenvolvimento do raciocínio e das atividades de expressão da criança, e a sua integração no meio físico e social

Art. 27. O ensino primário é obrigatório a partir dos sete anos e só será ministrado na língua nacional. Para os que o iniciarem depois dessa idade poderão ser formadas classes especiais ou cursos supletivos correspondentes ao seu nível de desenvolvimento.

Art. 31. As empresas industriais, comerciais e agrícolas, em que trabalhem mais de 100 pessoas, são obrigadas a manter ensino primário gratuito para os seus servidores e os filhos desses (BRASIL, 1961).

Mesmo o enfoque principal destes artigos sendo a criança, tratam também da educação de jovens e adultos que iniciam com idade superior, possibilitando os cursos supletivos, a diversidade de métodos e formas de atividade escolar e de experiências com finalidade de aprimorar os processos educativos. Além disso, traz a obrigatoriedade de oferta de ensino 
primário com objetivos de desenvolvimento de raciocínio e integração no meio físico e social por parte de empresas que tenham mais de 100 funcionários.

Como resultado dos movimentos populares, que surgem a partir dos governos desenvolvimentistas dotados de uma racionalidade incompatível com a realidade brasileira, a incapacidade de manter a administração provocou um certo descontentamento e um desequilíbrio financeiro para a nação. Nesse período, a "questão da democracia, da participação política e a disputa pelos votos ocupavam boa parte do tempo social" (HADDAD; DI PIERRO, 2000, p. 112) configurando um campo de constantes disputas.

Os debates em torno de uma educação popular tomam força, assim como as propostas de Paulo Freire. Destacam-se o conceito de cultura popular, assumido como fundamental, do qual passou a derivar o conceito de educação popular - valorização da cultura popular em detrimento à cultura erudita; a educação como dimensão política e a luta por um novo projeto histórico. Nessa linha, a luta por melhores condições de vida e o envolvimento dos setores sociais ganham espaço, porque surge nesses grupos a educação de base voltada para a educação de adultos como uma estratégia de atuação na política.

Em 1964, com o início do governo militar, surge um estágio de perseguição e repressão aos modos populares de educação, seus idealizadores foram exilados. Há uma tendência para a formação tecnicista, a educação se torna instrumento de homogeneização e controle da população. Assim, o Estado coercitivo tinha o objetivo de acabar com os ideais políticos e "normalizar" as relações sociais.

No início da década de 1960, a educação de adultos era vista de modo diferente. No entanto, as pessoas passaram a relacionar o termo "analfabeto" com alguém sem instrução ou conhecimento. Contudo, Freire (1987) não concordava com aquela visão de que pessoas analfabetas fossem consideradas sem conhecimento.

Algumas leis e reformas posteriores consideram os analfabetos como dependentes e incapazes. O Decreto $\mathrm{n}^{\mathrm{o}} 3.029$, de 9 de janeiro de 1881, que também ficou conhecido como "Lei Saraiva" e teve como redator final o Deputado Geral Rui Barbosa, corrobora com a ideia de incapacidade dos analfabetos restringindo o voto aos alfabetizados, sendo garantido por lei a exclusão da pessoa analfabeta. A proibição do voto da pessoa analfabeta imperou até 1985, quando votaram pela primeira vez em eleições municipais.

Neste aspecto, Scortegagna e Oliveira (2006) observam que Freire trouxe um marco na educação de adultos, onde ele elaborou uma metodologia que trabalha a ideia de educação 
sendo um ato que poderia ser considerado tanto um instrumento de submissão como também um instrumento de libertação, dependendo apenas de como o povo enxergava a alfabetização.

As ideias de Paulo Freire para uma educação libertadora foram fortemente perseguidas e o que imperou durante o projeto nacional-desenvolvimentista foi a formação para o trabalho, com a pedagogia tecnicista sendo a que mais atendia à demanda do pleno emprego e da formação com o desenvolvimento de habilidades e competências para o trabalho.

No período de redemocratização do país, onde estes projetos de desenvolvimento apresentam sinais de esgotamento, ampliam-se as discussões na educação em torno da formação apenas para o trabalho, considerando o homem como ser social que deve ser preparado para a vida.

\begin{abstract}
Ao longo dos anos 1980, a luta dos educadores comprometidos com a educação pública e a superação das desigualdades de classe em todas as suas expressões e, particularmente, na educação, foi pela defesa da educação unitária, omnilateral e politênica. No confronto das forças políticas vitoriosas no Congresso Nacional e a eleição de Fernando Henrique Cardoso, aprovou-se a Lei n ${ }^{\circ}$ 9.394/96 cuja tônica não foi mais a de preparação para o trabalho e sim para a vida, ressaltando uma falsa dicotomia só explicável pelo estigma escravocrata de nossa sociedade. Sob esse ideário, preparar para a vida significaria desenvolver nas pessoas competências genéricas e flexíveis, de modo que elas pudessem se adaptar facilmente às incertezas do mundo contemporâneo (CIAVATTA; RAMOS, 2011, p. 30).
\end{abstract}

A década de 1980 foi marcada pela luta progressista que discutia um projeto de educação que pensasse também na classe trabalhadora, visando a superação da "dualidade estrutural" e defendida por Ramos (2014) como uma "concepção de educação politécnica, pela qual se buscava romper com a dicotomia entre educação básica e técnica, resgatando o princípio da formação humana em sua totalidade" (RAMOS, 2014, p. 16), mas este projeto sofreu uma derrota para os conservadores em 1990, quando foi aprovado outro projeto de Lei de Diretrizes e Bases (LDB), que não contemplava a totalidade das ideias progressistas.

A partir da Constituição Federal de 1988, considerada a "Constituição Cidadã", foram implementados alguns documentos normativos que norteiam a Educação Básica e a EJA, conforme apresentado no Quadro 1.

Quadro 1 - Marcos Legais

\begin{tabular}{|c|l|l|}
\hline Década & \multicolumn{1}{|c|}{$\mathbf{N}^{\mathbf{0}}$ / data } & \multicolumn{1}{c|}{ Principais deliberações } \\
\hline 1980 & Constituição de 1988 & $\begin{array}{l}\text { Conhecida como Constituição Cidadã, foi aprovada durante o processo } \\
\text { de redemocratização do país e é um marco aos direitos dos cidadãos } \\
\text { brasileiros, por garantir liberdades civis e os deveres do Estado. }\end{array}$ \\
\hline 1990 & $\begin{array}{l}\text { Lei } \mathrm{n}^{\circ} \text { 8.069, de } 13 \text { de } \\
\text { julho de } 1990\end{array}$ & $\begin{array}{l}\text { Documento Legal que busca dar proteção a Criança e o Adolescente, } \\
\text { inclusive o direito à educação. }\end{array}$ \\
\hline
\end{tabular}




\begin{tabular}{|c|c|c|}
\hline & $\begin{array}{l}\text { Lei } n^{\circ} 9.394 \text {, de } 20 \text { de } \\
\text { dezembro de } 1996\end{array}$ & $\begin{array}{l}\text { Possibilidade da Educação de Jovens e Adultos articulada com a } \\
\text { educação profissional. Regulamenta os cursos supletivos. }\end{array}$ \\
\hline & $\begin{array}{l}\text { Decreto } n^{\circ} 2.208 \text {, de } \\
17 \text { de abril de } 1997\end{array}$ & $\begin{array}{l}\text { Desarticula a formação básica da formação profissional reforçando o } \\
\text { Dualismo estrutural histórico da educação no Brasil. }\end{array}$ \\
\hline \multirow{3}{*}{2000} & $\begin{array}{l}\text { Lei } n^{\circ} 10.172 \text {, de } 9 \text { de } \\
\text { janeiro de } 2001\end{array}$ & $\begin{array}{l}\text { O Plano Nacional de Educação foi elaborado com objetivos e metas para } \\
\text { educação a cada dez anos. O primeiro foi elaborado em } 1996 \text { para } \\
\text { vigorar entre } 2001 \text { e } 2010 \text {. }\end{array}$ \\
\hline & $\begin{array}{l}\text { Decreto } n^{\circ} 5.154 \text {, de } \\
23 \text { de julho de } 2004\end{array}$ & $\begin{array}{l}\text { Revoga o Decreto } 2.208 \text {, de } 1997 \text {, possibilitando a integração da } \\
\text { formação geral com a formação profissional. }\end{array}$ \\
\hline & $\begin{array}{l}\text { Decreto } n^{\circ} 5.478, \text { de } \\
24 \text { de junho de } 2005 \\
\text { Decreto } n^{\circ} 5.840 \text {, de } \\
13 \text { de julho de } 2006\end{array}$ & $\begin{array}{l}\text { Inicialmente Institui, no âmbito federal, o Programa Nacional de } \\
\text { Integração da Educação Profissional com a Educação Básica na } \\
\text { Modalidade de Educação de Jovens e Adultos, posteriormente } \\
\text { ampliando sua abrangência e princípios pedagógicos. }\end{array}$ \\
\hline 2010 & $\begin{array}{l}\text { Lei } n^{\circ} 13.005 \text {, de } 25 \\
\text { de junho de } 2014\end{array}$ & $\begin{array}{l}\text { Aprova o Plano Nacional de Educação (PNE) com metas ambiciosas } \\
\text { para o período de } 2014 \text { a } 2024 \text {, para educação de jovens e adultos com a } \\
\text { meta } 10 \text {, de oferecer, no mínimo, } 25 \% \text { (vinte e cinco por cento) das } \\
\text { matrículas de educação de jovens e adultos, nos ensinos fundamental e } \\
\text { médio, na forma integrada à educação profissional. }\end{array}$ \\
\hline
\end{tabular}

Fonte: BRASIL, 1988; 1990; 1996; 1997; 2001; 2004; 2005; 2006; 2014.

Ao analisarmos os dados do Quadro 1, percebemos que mesmo a Constituição de 1988 estabelecendo os direitos dos cidadãos e as obrigações do Estado, e com todos os outros aparatos legais que lhe sucederam, ainda nos dias atuais não podemos dizer que estes direitos estão plenamente atendidos. Para Machado (2016), entender a educação nos dias atuais exige compreender que existe tradições enraizadas no pensamento e nas políticas de educação como direito de todos. Além disso,

[...] para quem acompanha a luta histórica do direito à educação para jovens e adultos trabalhadores no Brasil. Nesse sentido, há um passado que não passou, que é o do preconceito com pobres, negras e negros, população que vive no campo ou nas periferias das cidades, que são a maioria daqueles que ainda não concluíram a educação básica, mesmo já tendo passados mais de duas décadas da aprovação da CF de 1988 (MACHADO, 2016, p. 434).

Em busca de corrigir essas injustiças e desigualdades da classe trabalhadora, consideramos as ideias de Paulo Freire, atuais no sentido da autonomia e senso crítico, para que, a partir de então, reconhecer a realidade a partir de questionamentos possa superar a situação de opressão e melhore as condições de vida das pessoas inseridas nesse contexto da educação popular.

\section{Contribuições de Paulo Freire na EducaÇÃo de Jovens e Adultos no Brasil}

Nascido no Recife, capital do estado de Pernambuco, o professor e intelectual Paulo Freire trouxe reflexões ideológicas sobre a educação como instrumento de libertação, que a região nordestina é caracterizada por sua escassez e precariedade. No entanto, Freire 
caracterizou o Estado de Pernambuco como "epicentro nordestino de situação humana, social e política” (JORGE, 1981, p. 7).

Paulo Freire contribuiu de forma grandiosa no Brasil, com o processo da educação de jovens e adultos, atualmente conhecido como EJA. Ele alavancou a necessidade da alfabetização de todas as idades, independentemente de sua classe, raça, ou condição financeira.

A busca por uma educação que vai além de ler e escrever, de um autoconhecimento, e, com isso, a libertação de uma venda que não nos permite ver a situação de exploração em que vivemos e ainda dar um sentido de conformidade com a situação, é a essência da educação pregada por Paulo Freire.

Se nos reportarmos aos movimentos populares de educação, da primeira metade da década de 1960, recordamos ali a defesa de uma visão emancipatória de educação, para usar um termo freiriano, e que ainda luta bravamente para se manter viva no meio dos educadores brasileiros (MACHADO 2016, p. 431).

Torres (2002) comenta que a atitude de Freire para com a educação de jovens e adultos foi de fomentar uma educação popular, que alcance a maioria e até toda a população, sendo um direito todos serem alfabetizados. A EJA é diferenciada na prática pedagógica, visto que o professor está à frente de uma turma com certa heterogeneidade de idades buscando uma educação. A turma precisa de motivação e incentivo e, para isso, é necessário que o professor tenha habilidade e esteja disposto a repensar e reinventar sua prática, utilizando-se de meios diversos para alcançar esse público. O aluno da EJA se encontra, na maioria das vezes, em um processo de redescoberta da educação, vindo de um histórico de abandono e exclusão, sendo a maioria de origem da classe trabalhadora. Assim, esses alunos participam de maneira árdua no aprendizado, buscando sempre saciar a vontade de conseguir ler um livro sozinho, ou mesmo escrever uma carta, ou, ainda, aprimorar e elevar os níveis escolares.

Neste aspecto o professor precisa acreditar na capacidade de seus alunos:

Acreditar na capacidade de aprender de cada um constitui-se fator preponderante para o resgate da auto-confiança, indispensável na aprendizagem, porém desacreditada e marginalizada, ao longo de praticamente todas as suas experiências, junto à sociedade letrada (FUCK, 2002, p. 92).

A teoria desenvolvida por Freire era sustentada por seu discurso, onde, ainda que o professor estimule o aluno a aprender, o aluno deveria acreditar em sua capacidade própria; o professor não tem domínio sobre a força do aluno de acreditar que é capaz de ser alfabetizado.

Toda e qualquer técnica que, antecipadamente, estabeleça passos a serem uniformemente seguidos, não tem condições de atingir minimamente os alfabetizandos adultos, que por via de regra se concentraram em classes populares, uma vez que não levam em conta esse processo, pelo qual passa o alfabetizando, 
moldando o ensino somente na lógica do sistema da escrita. E neste caso até se alfabetiza, ou seja, se transforma homens em robôs. Na medida, porém que esses robôs perderem seus programadores (professores), perde também sua ação (FUCK, 2002, p. 92).

Outra influência teórico-metodológica do intelectual Paulo Freire na EJA pode ser apreendida na crítica em relação às "cartilhas de estudo", vistas sob sua ótica sem sentido real ou de apropriação às práticas individuais ou coletivas dos sujeitos que participavam dos processos de alfabetização. Logo, os alunos apenas decoravam as palavras, mas não aprendiam. Freire defendia que o aluno para dominar o processo de ler e escrever precisava ter autonomia para aprimorar seu aprendizado.

Socialmente e culturalmente, a pessoa letrada já não é a mesma que era quando analfabeta ou iletrada, ela passa a ter outra condição social e cultural - não se trata propriamente de mudar de nível ou de classe social, cultural, mas de mudar seu lugar social, seu modo de viver na sociedade, sua inserção na cultura - sua relação com os outros, com o contexto, com os bens culturais torna-se diferente (SOARES, 2003, p. 37).

Deste modo, Paulo Freire teve influência direta na educação de jovens e adultos. Em decorrência disto, escolas que possuem a EJA em suas dependências citam o método Paulo Freire. A metodologia desenvolvida por Freire, no entanto, não é aplicada em sua totalidade, mas isso porque seu método consiste em uma forma onde o professor deveria ter mais tempo para se aprofundar e, assim, abordar de forma profunda os conteúdos didáticos. Contudo, atualmente a LDB não garante condições para sua efetivação, os currículos são engessados e não permitem flexibilização, o que dependeria de mais tempo com menor quantidade de alunos para sua aplicação e, como consequência, o professor acaba tendo que abordar de maneira seletiva e, às vezes, superficial os conteúdos didáticos.

Nota-se, portanto, que o método de Freire não se efetiva na prática nas unidades escolares com EJA. Assim, o que é visto atualmente de influência de Paulo Freire nas escolas de modo geral, é o estímulo ao diálogo, os círculos de discussão de leitura, seminários, a valorização da cultura local e com os temas geradores. Isso tudo para que os alunos tenham interação, percebam sua evolução e de seus colegas, apropriem-se de conceitos que poderão nortear suas ações com relação as decisões cotidianas.

\section{CONCEPÇões de EdUCAÇÃo, de ENSINO E APRENDIZAGEM EM DISPUTA NO CAMPO DA EJA}

Para entendermos o cenário atual da EJA, precisamos recorrer as políticas públicas que fomentam essa formação e a quem essas políticas atendem. Além disso, é preciso entender 
também como hoje têm sido aplicadas as adaptações curriculares indicadas por Paulo Freire a partir do contexto do aluno. Se, no ambiente escolar, estão organizados espaços de discussão a respeito dessa modalidade de ensino ou continua com o caráter de generosidade arraigado na história da educação de jovens e adultos no Brasil. As motivações para o aluno voltar à escola são diversas, mas a questão da evasão nessa modalidade de ensino é considerada alta principalmente entre os jovens de famílias mais pobres, o que nos faz refletir: se a escolarização proporciona melhores condições de vida e de trabalho, por que tantos jovens abandonam a escola?

Conforme divulgado pela Agência IBGE Notícias (2019), segundo dados do IBGE, em 2018, cerca de $11,8 \%$ dos adolescentes com 15 a 17 anos de idade, que estavam entre os $20 \%$ da população com os menores rendimentos, abandonaram a escola sem concluir o Ensino Básico, um percentual 8 vezes maior que o desse mesmo grupo etário entre os $20 \%$ com maiores rendimentos $(1,4 \%)$.

Outro dado preocupante revelado pelo IBGE é que cerca de $40 \%$ da população brasileira tinha pouca instrução ou não tinha concluído o Ensino Fundamental e ainda mantém uma taxa de analfabetismo de $8 \%$ de sua população com idade igual ou superior a 15 anos. Isso indica que a legislação por si só não cumpre o objetivo de universalização da Educação Básica, pois muitos destes jovens ficaram em algum momento à margem do processo e foram deixados para trás. Outro fator muito preocupante são os analfabetos funcionais, aqueles que reconhecem as letras, no entanto, não são capazes de interpretar textos simples e nem fazer cálculos em situações mais abstratas.

Estudos feitos pelo Instituto Paulo Montenegro e pela Organização Não-Governamental (ONG) Ação Educativa, que apontam o Indicador de Alfabetismo Funcional (INAF), em 2019, indicam que $30 \%$ dos brasileiros são considerados analfabetos funcionais e apenas $12 \%$ da população pode ser considerado proficiente; então, mesmo com as políticas de alfabetização estamos formando sujeitos incapazes de desenvolver pensamento crítico, uma vez que mal sabem decifrar as letras e números.

A partir destes dados, podemos perceber que a questão do analfabetismo e a má formação dos sujeitos de alguma forma atende um determinado interesse do capital que precisa manter um certo número de força de trabalho disponível para manter a exploração e também precisa manter um certo número de pessoas sem qualificação como forma de estabelecer o conformismo com sua situação de privação de direitos. 
Diante disso, os currículos são pensados como propostas fora de contexto da realidade dos alunos, seus projetos pessoais não são considerados e a prioridade é por uma formação aligeirada que não atende a proposta de Paulo Freire no sentido de uma educação libertadora:

[...] se o homem é capaz de perceber-se, enquanto percebe uma realidade que lhe parecia "em si" inexorável, é capaz de objetivá-la, descobrindo sua presença criadora e potencialmente transformadora desta mesma realidade. O fatalismo diante da realidade, característico da percepção distorcida, cede seu lugar à esperança. Uma esperança crítica que move os homens para a transformação (FREIRE, 1983, p. 27).

Se não temos grandes possibilidades com essa modalidade que caminha para uma forma ainda mais tecnicista com a Educação à Distância (EAD), proposta por várias instituições, temos, por outro lado, projetos que podem proporcionar o mínimo de formação para a vida do educando, para além da questão mercadológica, como é o caso do Proeja. O que tem de fragilidade é que os programas têm fim, como vimos ao longo da história da EJA no Brasil. O que seria indicado seria uma política de Estado e não de Governo, assim teria continuidade e evitaria a desconstrução que ocorre nas políticas públicas de acordo com a visão ideológica de cada governo.

A proposta do Proeja, conforme se apresenta,

Está inscrita no marco da construção de um projeto possível de sociedade mais igualitária e fundamenta-se nos eixos norteadores das políticas de educação profissional atualmente vigentes: a expansão da oferta pública de educação; o desenvolvimento de estratégias de financiamento público que permitam a obtenção de recursos para um atendimento de qualidade; a oferta de educação profissional dentro da concepção de formação integral do cidadão (Ensino Médio Integrado à Educação Profissional Técnica de Nível Médio) - formação esta que combine, na sua prática e nos seus fundamentos científico-tecnológicos e histórico-sociais, trabalho, ciência e cultura - e o papel estratégico da educação profissional nas políticas de integração social (MOURA, 2006, p. 3).

Para Ramos (2020), a finalidade do Ensino Médio integrado gira em torno de disputas de formar para o mercado de trabalho ou formar para que o aluno possa compreender a realidade como uma práxis histórica de produção e reprodução da existência humana ${ }^{2}$. Desta forma, o conhecimento nos possibilita compreender que mundo é este, o que fazemos neste mundo, e como esse mundo se fez desta forma, e a dimensão econômica estritamente relacionada ao mercado de trabalho é uma das mediações ou contradições desta realidade.

A relação econômica não pode ser considerada simplesmente como vinculada ao emprego, do ponto de vista da classe trabalhadora, e da geração de lucro e acumulação do

\footnotetext{
2 Marise Nogueira Ramos participou de uma transmissão ao vivo para discutir o Ensino Médio Integrado frente a uma pandemia junto ao Movimento por uma Escola Popular do Sinasefe e mencionou em maiores detalhes esta visão. Vídeo disponível em: https://www.youtube.com/watch?v=WVl5n_5VDd8.
} 
capital, segundo anseios da burguesia. O trabalho é uma dimensão histórica de como a sociedade foi estruturada; reconhecer e compreender essa dinâmica é o princípio fundamental do Ensino Médio integrado que tem o trabalho como princípio educativo.

\section{CONSIDERAÇÕES FINAIS}

A evolução da educação de Jovens e Adultos desde o período colonial perpassa por diversos estágios e concepções. De ato de generosidade ao direito institucionalizado foi um longo caminho, e pode-se considerar recente a preocupação do Brasil com a questão dos não escolarizados. Ainda assim, por pressão de organismos internacionais que financiaram boa parte da educação e pelo processo de industrialização.

O período militar foi um período tenso, marcado por ataques e imposições típicas de regimes de governo autoritário, para as Universidades e para os movimentos sociais organizados atuantes na educação. O Estado militar promoveu uma série de reformas na educação, começando pelo Ensino Superior (1968), depois nos outros níveis de ensino (1971), ampliando as funções atribuídas a educação como qualificação, socialização, integração para a vida social passando a ser um instrumento que serviria para o projeto de sociedade passiva que atendesse aos interesses do capital.

Durante o período de ditadura militar, com ideias desenvolvimentistas, era adequado que a educação se aliasse com os interesses econômicos, ou seja, a educação vista como potencial econômico, com desenvolvimento de competências e habilidades que atendessem à demanda por capital humano, força de trabalho. Essa pedagogia tecnicista foi imperativa desde a década de 1970, no Brasil.

Com o fim do regime militar e o processo de redemocratização do país, há uma retomada das discussões em torno de uma formação integral, politécnica e libertadora. Alguns marcos legais devem ser considerados ao falarmos do processo de redemocratização, com destaque da Constituição Cidadã, a nova LDB que garante a Educação Básica para todos e os planos nacionais de educação que traçam as diretrizes e metas para a educação a cada dez anos.

As contribuições de Paulo Freire para a EJA foram e continuam sendo de fundamental importância. As políticas educacionais são descontinuadas, há um descolamento da educação com as questões do mundo do trabalho, tendo o Proeja como uma possibilidade para a integração e superação da dualidade educacional.

Atualmente a modalidade de EJA ainda enfrenta, com maiores implicações, a questão da evasão e baixo aproveitamento. A pandemia de coronavírus deixou mais evidente as questões 
das desigualdades sociais, com o agravante do uso de tecnologia inacessível para muitos brasileiros.

Assim, as políticas e concepções da educação de jovens e adultos continuam sendo um campo de disputas, que podem tanto servir para potencializar a perpetuação da situação desigual da sociedade de classes, como podem oportunizar a emancipação. Nesse sentido, o que se precisa é evidenciar mais as experiências exitosas, para que outros sujeitos à margem do processo educacional possam se identificar e acreditar na educação da esperança, que transforma vidas.

\section{REFERÊNCIAS}

BRASIL. Constituição Política do Império do Brasil (Texto Outorgado em 1824). In: BRASIL. Senado Federal. Constituições brasileiras. v. 1. 3. ed. Brasília: Senado Federal, Subsecretaria de Edições Técnicas, 2012.

BRASIL. Constituição Federal (Texto Promulgado em 1988). Disponível em: http://www. senado.leg.br/atividade/const/con1988/CON1988_05.10.1988/ind.asp. Acesso em 25 fev. 2021.

BRASIL. Decreto $\mathbf{n}^{0}$. 3.029, de 9 de janeiro de 1981. Reforma a legislação eleitoral. Disponível em: https://www2.camara.leg.br/legin/fed/decret/1824-1899/decreto-3029-9janeiro-1881-546079-norma-pl.html. Acesso em 26 fev. 2021.

BRASIL. Decreto $\mathbf{n}^{0}$. 2.208, de 17 de abril de 1997. Regulamenta o $\S 2^{\circ}$ do art. 36 e os arts. 39 a 42 da Lei $\mathrm{n}^{\circ}$ 9.394, de 20 de dezembro de 1996, que estabelece as diretrizes e bases da educação nacional. Disponível em: http://www2.camara.leg.br/legin/fed/decret/1997/decreto2208-17-abril-1997-445067-norma-pe.html. Acesso em 25 fev. 2021.

BRASIL. Decreto $\mathbf{n}^{\mathbf{0}}$. 5.154, de 23 de julho de 2004. Regulamenta o $\S 2^{\circ}$ do art. 36 e os arts. 39 a 41 da Lei n $^{\circ}$ 9.394, de 20 de dezembro de 1996, que estabelece as diretrizes e bases da educação nacional, e dá outras providências. Disponível em: http://www2.camara.leg.br/legin/ fed/decret/2004/decreto-5154-23-julho-2004-533121-norma-pe.html. Acesso em 25 fev. 2021.

BRASIL. Decreto $\mathbf{n}^{\mathbf{0}}$. 5.478, de 24 de junho de 2005. Institui, no âmbito das instituições federais de educação tecnológica, o Programa de Integração da Educação Profissional ao Ensino Médio na Modalidade de Educação de Jovens e Adultos - PROEJA. Disponível em: http://www2.camara.leg.br/legin/fed/decret/2005/decreto-5478-24-junho-2005-537577norma-pe.html. Acesso em 25 fev. 2021.

BRASIL. Decreto $\mathbf{n}^{\circ}$. 5.840, de 13 de julho de 2006. Institui, no âmbito federal, o Programa Nacional de Integração da Educação Profissional com a Educação Básica na Modalidade de Educação de Jovens e Adultos - PROEJA, e dá outras providências. Disponível em: http:// www2.camara.leg.br/legin/fed/decret/2006/decreto-5840-13-julho-2006-544587-normape.html. Acesso em 25 fev. 2021. 
BRASIL. Lei $\mathbf{n}^{\circ}$. 4.024, de 20 de dezembro de 1961. Fixa as Diretrizes e Bases da Educação Nacional. Disponível em: https://www2.camara.leg.br/legin/fed/lei/1960-1969/lei-4024-20dezembro-1961-353722-norma-pl.html. Acesso em 26 fev. 2021.

BRASIL. Lei no ${ }^{\circ}$ 8.069, de 13 de julho de 1990. Dispõe sobre o Estatuto da Criança e do Adolescente, e dá outras providências. Disponível em: https://www2.camara.leg.br/legin/fed/ lei/1990/lei-8069-13-julho-1990-372211-norma-pl.html. Acesso em 25 fev. 2021.

BRASIL. Lei $\mathbf{n}^{0}$. 9.394, de 20 de dezembro de 1996. Estabelece as diretrizes e bases da educação nacional. Disponível em: https://www2.camara.leg.br/legin/fed/lei/1996/lei-939420-dezembro-1996-362578-norma-pl.html. Acesso em 25 fev. 2021.

BRASIL. Lei no ${ }^{\mathbf{1 0}}$ 10.172, de 9 de janeiro de 2001. Aprova o Plano Nacional de Educação e dá outras providências. Disponível em: http://www2.camara.leg.br/legin/fed/lei/2001/lei10172-9-janeiro-2001-359024-norma-pl.html. Acesso em 25 fev. 2021.

BRASIL. Lei $\mathbf{n}^{\mathbf{0}}$. 13.005, de 25 de junho de 2014. Aprova o Plano Nacional de Educação PNE e dá outras providências. Disponível em: http://www2.camara.leg.br/legin/fed/lei/2014/ lei-13005-25-junho-2014-778970-norma-pl.html. Acesso em 25 fev. 2021.

BRASIL. Ministério da Educação e do Desporto. Secretaria de Educação Fundamental. Educação para Jovens e Adultos: Ensino Fundamental - Proposta curricular - $1^{\circ}$ segmento. Brasília: MEC, 2001; São Paulo: Ação Educativa, 2001.

CAIRES, Vanessa Guerra; OLIVEIRA, Maria Auxiliadora Monteiro. Educação profissional brasileira: da colônia ao PNE 2014-2024. Petrópolis: Vozes, 2016.

CIAVATTA, Maria; RAMOS, Marise. Ensino Médio e Educação Profissional no Brasil Dualidade e fragmentação. Revista Retratos da Escola, v. 5, n. 8, p. 27 - 41, jan./jun. 2011. Disponível em: http://retratosdaescola.emnuvens.com.br/rde/article/viewFile/45/42. Acesso em 25 fev. 2021.

FÁVERO, Osmar; FREITAS, Marinaide. A educação de jovens e adultos: um olhar sobre o passado e o presente. Revista Inter Ação, v. 36, n. 2, p. 365 - 392, 28 dez. 2011. Disponível em: https://www.revistas.ufg.br/interacao/article/view/16712. Acesso em 25 fev. 2021.

FÁVERO, Osmar. O legado de Paulo Freire: passado ou atualidade?. Revej@ - Revista de Educação de Jovens e Adultos, v. 1, p. 39 - 44, ago/2007. Disponível em: https://www.usfx.bo/nueva/vicerrectorado/citas/SOCIALES_8/Pedagogia/78.pdf. Acesso em: 26 fev. 2021.

FREIRE, Paulo. Educação e mudança. 8. ed. Rio de Janeiro: Paz e Terra, 1983.

FREIRE, Paulo. Pedagogia do Oprimido. 17. ed. Rio de Janeiro: Paz e Terra, 1987.

FREIRE, Paulo. A importância do ato de ler: em três artigos que se completam. São Paulo: Autores Associados; Cortez, 1989.

FREIRE, Paulo. Pedagogia da esperança: um reencontro com a pedagogia do oprimido. Rio de Janeiro: Paz e Terra, 1992. 
FREIRE, Paulo. Política e Educação. São Paulo: Cortez, 2001.

FUCK, Irene Terezinha. Alfabetização de adultos: relato de uma experiência construtivista. 8. ed. Petrópolis: Vozes, 2002.

GADOTTI, Moacir. Reinventando Paulo Freire no século 21. São Paulo: Editora e Livraria Instituto Paulo Freire, 2008.

GADOTTI, Moacir; ABRÃO, Paulo (orgs.). Paulo Freire: anistiado político brasileiro. Brasília: Comissão de Anistia, Ministério da Justiça, 2012.

GERMANO, José Willington. Estado militar e educação no Brasil: 1964/1985: um estudo sobre a política educacional. 1990. 444 f. Tese (Doutorado em Educação) - Faculdade de Educação, Universidade Estadual de Campinas. Campinas - SP, 1990. Disponível em: http://repositorio.unicamp.br/jspui/handle/REPOSIP/251894?mode=full. Acesso em: 27 fev. 2021.

GERMANO, José Willington. Estado militar e educação no Brasil. São Paulo: Cortez, 1993.

HADDAD, Sergio; DI PIERRO, Maria Clara. Escolarização de jovens e adultos. Revista Brasileira de Educação, n. 14, p. 108 - 330, 2000. Disponível em: https://www.scielo.br/pdf/ rbedu/n14/n14a07.pdf. Acesso em 25 fev. 2021.

IBGE. AGÊNCIA IBGE NOTÍCIAS. Editoria de Estatísticas Sociais. 11,8\% dos jovens com menores rendimentos abandonaram a escola sem concluir a educação básica em 2018. 6 de novembro de 2019. Disponível em: https://agenciadenoticias.ibge.gov.br/agencia-sala-deimprensa/2013-agencia-de-noticias/releases/25885-11-8-dos-jovens-com-menoresrendimentos-abandonaram-a-escola-sem-concluir-a-educacao-basica-em-2018. Acesso em 1 mar. 2021.

IBGE. Instituto Brasileiro de Geografia e Estatística. Coordenação de Trabalho e Rendimento. Pesquisa Nacional por Amostra de Domicílios Contínua - Educação: 2019. Rio de Janeiro: IBGE, 2020. Disponível em: https://biblioteca.ibge.gov.br/visualizacao/livros/ liv101736_informativo.pdf. Acesso em 1 mar. 2021.

JORGE, J. Simões. A ideologia de Paulo Freire. São Paulo: Loyola, 1981.

MACHADO, Maria Margarida. A educação de Jovens e Adultos Após 20 Vinte Anos da Lei n ${ }^{\circ}$ 9.394, de 1996. Revista Retratos da Escola, v. 10, n. 19, p. 429 - 451, 2016. Disponível em: http://retratosdaescola.emnuvens.com.br/rde/article/view/687. Acesso em 1 mar. 2021.

MELO, Cristiane Silva; MACHADO, Maria Cristina Gomes. Notas para a história da educação: considerações acerca do decreto $\mathrm{n}^{\circ}$ 7.247, de 19 de abril de 1879 , de autoria de Carlos Leôncio de Carvalho. Revista HISTEDBR On-line, v. 9, n. 34, p. 294-305, 2012. DOI: 10.20396/rho.v9i34.8639594. Disponível em: https://periodicos.sbu.unicamp.br/ojs/ index.php/histedbr/article/view/8639594. Acesso em: 26 fev. 2021.

MOURA, Dante Henrique. EJA: formação técnica integrada ao ensino médio. In: MINISTÉRIO DA EDUCAÇÃO. EJA: formação técnica integrada ao ensino médio. Boletim - Salto para o futuro: Secretaria de Educação a Distância, Brasília, n. 16, set. 2006. 
MUNANGA, Kabengele (org.). Superando o Racismo na Escola. 2. ed. Brasília: Ministério da Educação, Secretaria de Educação Continuada, Alfabetização e Diversidade, 2005.

OLIVEIRA, Marta Kohl de. Jovens e adultos como sujeitos de conhecimento e aprendizagem. Trabalho apresentado na XXII Reunião Anual da ANPEd. Revista Brasileira de Educação, Caxambu, n. 12, p. 59-73, set. 1999. Disponível em:

http://anped.tempsite.ws/novo_portal/rbe/rbedigital/RBDE12/RBDE12_06_MARTA_KOHL _DE_OLIVEIRA.pdf. Acesso em: 28 fev. 2021.

PAIVA, Jane; MACHADO, Maria Margarida; IRELAND, Timothy (orgs.). Educação de Jovens e Adultos: uma memória contemporânea (1996 - 2004). Brasília: Ministério da Educação/UNESCO, 2005.

PROJETO MEMÓRIA. Reaprendendo o Brasil. Disponível em: http://www. projetomemoria.art.br/PauloFreire/biografia/06_biografia_reaprendendo_o_brasil.html. Acesso em 26 fev. 2021.

RAMOS, Marise Nogueira: Ensino Médio Integrado frente ao contexto de pandemia. [S. 1.]: 2020. 1 vídeo (93min). Disponível em:

https://www.youtube.com/watch?v=WVl5n_5VDd8. Acesso em 1 mar. 2021.

RAMOS, Marise Nogueira. História e política da educação profissional. Curitiba: IFPR, 2014. Disponível em: https://curitiba.ifpr.edu.br/wp-content/uploads/2016/05/História-epolítica-da-educação-profissional.pdf. Acesso em 1 mar. 2021.

RIBEIRO, Darcy. Educação como prioridade. São Paulo: Global, 2018.

SAVIANI, Demerval. História das ideias pedagógicas no Brasil. Campinas: Autores Associados, 2007.

SCORTEGAGNA, Paola Andressa; OLIVEIRA, Rita de Cássia da Silva. Educação de Jovens e Adultos no Brasil: uma análise histórico-crítica. Revista Eletrônica de Ciências da Educação, v. 5, n. 2, nov. 2006. Disponível em: http://www.periodicosibepes.org.br/index. php/reped/article/view/287. Acesso em 24 fev. 2021.

SOARES, Magda. Letramento: um tema em três gêneros. 2. ed. Belo Horizonte: Autêntica, 2003.

STRELHOW, Thyeles Borcarte. Breve história sobre a educação de jovens e adultos no Brasil. Revista HISTEDBR On-line, v. 10, n. 38, p. 49-59, 2012. Disponível em: https://periodicos.sbu.unicamp.br/ojs/index. php/histedbr/article/view/8639689. Acesso em: 25 fev. 2021.

TORRES, Rosa Maria. Nove teses sobre alfabetização: reflexões em torno da experiência nicaraguense. In: GADOTTI, Moacir. História das ideias pedagógicas. São Paulo: Ática, 2002.

XAVIER. Maria E. S. P. Capitalismo e escola no Brasil: a constituição do liberalismo em ideologia educacional e as reformas do ensino. Campinas: Papirus, 1990. 